Supporting Information

to

\title{
Structure-Related Electrochemistry of Sulfur-Poly(acrylonitrile) Composite Cathode Materials for Rechargeable Lithium Batteries
}

J. Fanous, M. Wegner, J. Grimminger, Ä. Andresen and M. R. Buchmeiser*

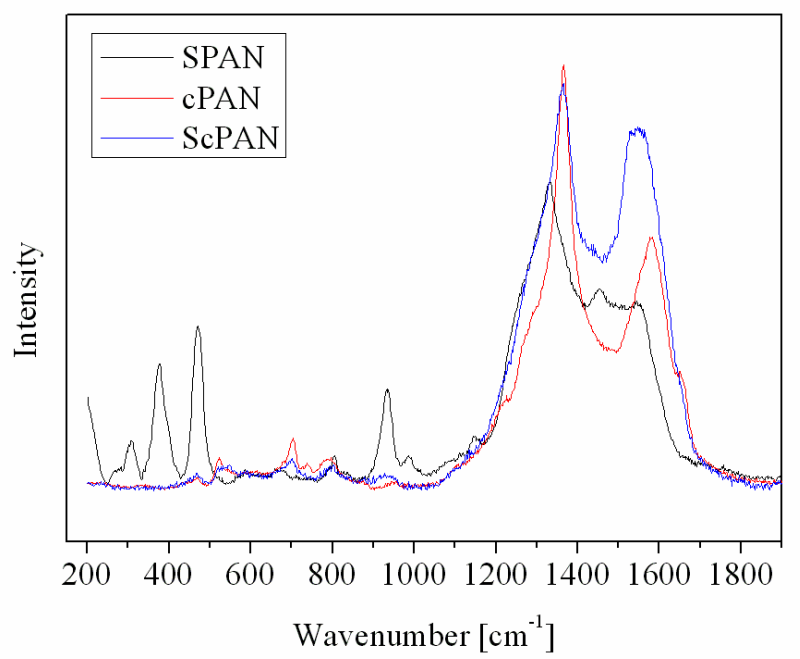

Figure S1. RAMAN spectrum of SPAN, cPAN and ScPAN. The intense signals around 1330 and $1560 \mathrm{~cm}^{-1}$ are assigned to the graphite D and $\mathrm{G}$ mode, those at $307 \mathrm{~cm}^{-1}, 379 \mathrm{~cm}^{-1}, 472$ $\mathrm{cm}^{-1}$ and $929 \mathrm{~cm}^{-1}$ are attributable to S-S deformation and stretch vibrations. 


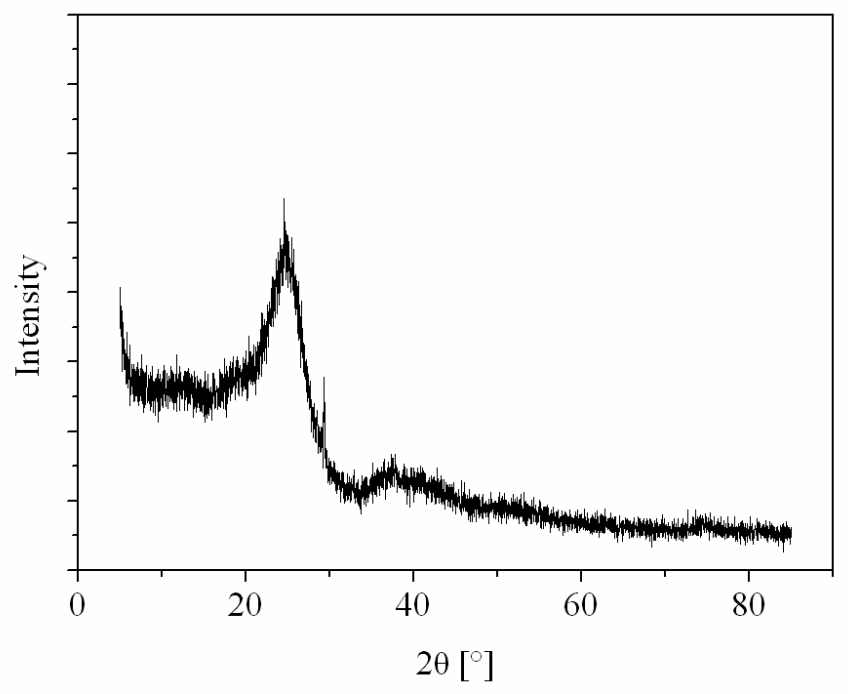

Figure S2. XRD spectrum of SPAN, lacking any signals for elemental sulfur.

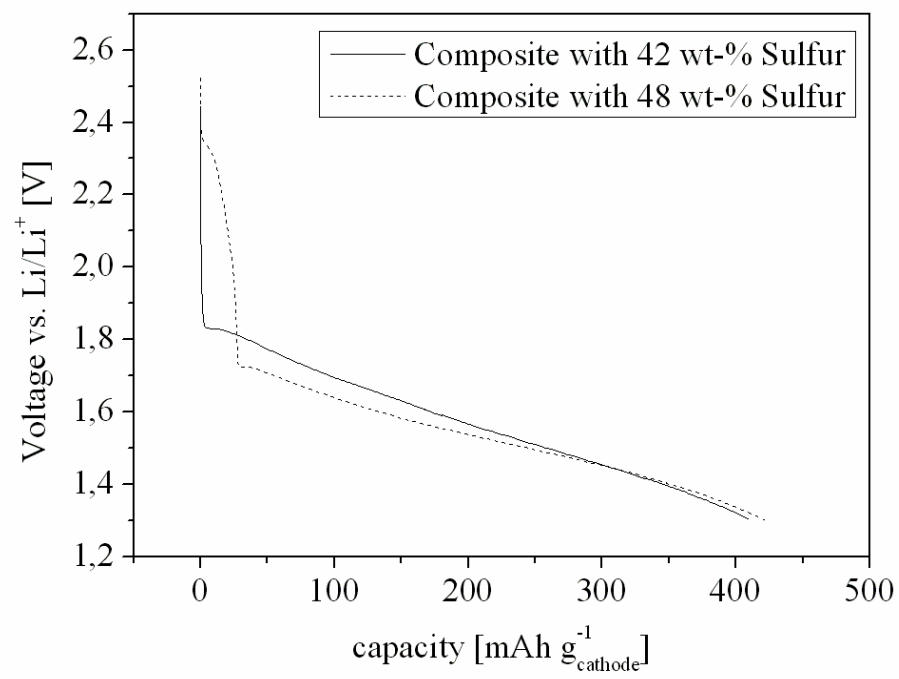

Figure S3. Voltage profile of the $1^{\text {st }}$ discharge for a cell having a sulfur content of a) 48 wt.$\%$ and b) $42 \mathrm{wt} .-\%$, respectively. Composite content in the cathode was $70 \mathrm{wt.} . \%$, cycling was carried out against lithium metal at $\mathrm{C} / 10$. 

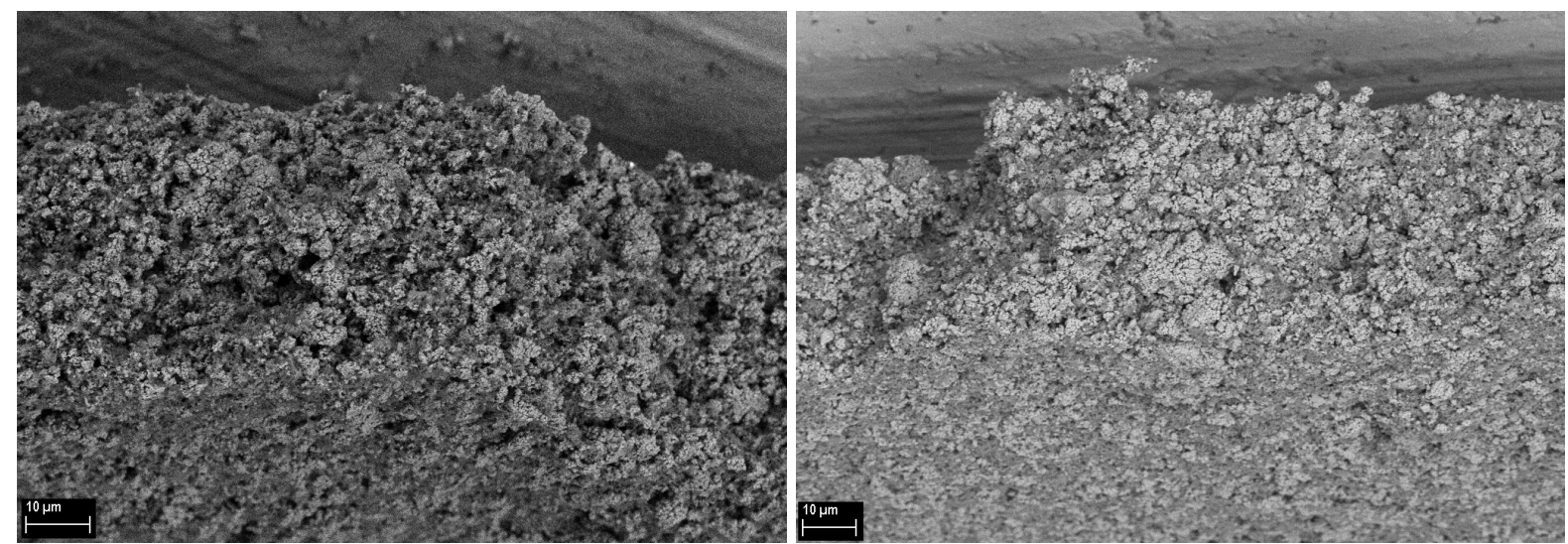

Figure S4. SEM pictures of a fresh (left) and a recharged (right) cathode (in ethers). No larger $\mathrm{S}_{8}$ aggregates are visible, suggesting a fine dispersion of $\mathrm{S}_{8}$ throughout the entire electrode.



Figure S5. XRD of a discharged cathode in a mixture of carbonates. The signals at $2 \Theta=37$, 44.5, 65 and 78 and 82 marked in red correspond to aluminum. 